\title{
A política como movimento indutor do trabalho coletivo nas escolas: o processo singular de implementação da Lei Federal 11.738/2008 no município de Curitiba
}

The policy to induce movement over the collective work in schools: the unique process of Federal Law 11,738 / 2008 implementation in Curitiba, Brazil

\section{La política para inducir el movimiento sobre el trabajo colectivo en las escuelas: el proceso único de aplicación de la Ley Federal 11.738 / 2008 en Curitiba, Brasil}

\section{Douglas Danilo Dittrich ${ }^{1}$ Maíra Gallotti Frantz ${ }^{2}$ Waldirene Sawozuk Bellardo ${ }^{3}$}

\section{Resumo}

O pressuposto subjacente à construção deste trabalho acentua a capacidade do ente federado municipal de responder, de modo singular, às demandas inscritas na agenda nacional a partir das lacunas que circunscrevem o campo das políticas públicas e potencializam as disputas pelos distintos significados que assumem a produção das soluções para o problema posto na agenda. Nesse ínterim, intenta-se explicitar o modo peculiar de resposta dada pela Secretaria Municipal da Educação de Curitiba à demanda nacional de ampliação do tempo destinado à hora-atividade - prevista na Lei Federal 11.738/2008 (Lei do Piso). Aspecto indelével na análise deste trabalho diz respeito ao princípio da simultaneidade existente entre os distintos lócus de produção e significação das políticas. Destarte, a despeito dos movimentos contrários, dos obstáculos e das contradições próprias da movimentação política, o município de Curitiba elaborou um novo projeto de organização escolar, o qual potencializou pedagogicamente os preceitos legais da Lei Federal do Piso Nacional no que tange à horaatividade, ressignificando a Permanência e induzindo o trabalho coletivo no interior das escolas. Este movimento político de reinterpretação e ressignificação da demanda local frente a uma determinada política nacional foi analisado e sistematizado neste trabalho a partir dos pressupostos teóricos da Abordagem Sequencial.

Palavras-chave: Política Educacional; Poder; Hora-atividade; Trabalho coletivo; Lei do Piso Salarial Nacional.

1 Mestre em Educação (UFPR). Secretaria Municipal de Educação de Curitiba - Brasil. Universidade Federal do Paraná (UFPR) - Brasil douglasdanilodittrich@gmail.com 


\begin{abstract}
The assumption underlying the construction of this work highlights the capacity of the municipalities to respond in a unique way, the demands inscribed on the national agenda from the gaps that circumscribe the field of public policies and enhance the disputes by the different meanings that take the production of solutions to the problem put on the agenda. Meanwhile, attempts to explain the peculiar way of response given by the Curitiba Department of Education to national demand for extension of time for teachers prepare classes and organize their activities (time-activity) - pursuant at Federal Law 11,738 / 2008. Indelible aspect in the analysis of this work relates to the principle of existing simultaneity between the different locus of production and significance of policies. Thus, despite the contrary movements of the obstacles and contradictions of the political movement, the city of Curitiba has produced a new school organization project, which pedagogically potentiate the legal provisions of the Federal Law with regard to time-activity, giving new meaning to the time work and inducing the collective work within schools. This political movement of reinterpretation and reframing the local front demand to a particular national policy was analyzed and systematized in this work from the theoretical assumptions of the Sequential Approach.
\end{abstract}

Keywords: Educational Policy; Power; Time-activity; Collective work; Minimum National Wage Law.

\title{
Resumen
}

El supuesto que subyace a la construcción de este artículo pone de relieve la capacidad de la entidad federal municipal para responder de una manera única, las demandas inscritas en la agenda nacional considerando las lacunas que circunscriben el campo de las políticas públicas y hacen crescer las controversias por los diferentes significados que se llevan a la producción de soluciones al problema de la agenda. Mientras tanto, buscase explicar la forma peculiar de la respuesta dada por el Dipartamento Municipal de Educación de Curitiba a la demanda nacional de extensión de tiempo para el tiempoactividad - de conformidad con la (Ley de sueldo mínimo a los docentes) Ley Federal 11.738 / 2008. Aspecto indeleble en el análisis de este trabajo se refiere al principio de la simultaneidad existentes entre los distintos locus de la producción y la importancia de las políticas. Por lo tanto, a pesar de los movimientos contrarios de los obstáculos y contradicciones del movimiento político, la ciudad de Curitiba ha producido un nuevo proyecto de la organización escolar, que pedagógicamente influencia las disposiciones legales de la Ley Federal con respecto al tiempo-actividad, dando un nuevo significado a la noción de permanencia de los docentes en las escuelas y a la inducción del trabajo colectivo dentro de las escuelas. Se analizó este movimiento político de reinterpretación y reformulación de la demanda local frente al de una política nacional en particular y sistematizado en este trabajo a partir de los supuestos teóricos del Enfoque Secuencial.

Palabras clave: Política educacional; Poder; Tiempo-actividad; Trabajo colectivo; Ley de Salarios Minímos Nacional a los Docentes. 
Ao iniciar este diálogo, que tem como foco a discussão acerca da centralidade do trabalho coletivo no interior da escola e da capacidade política do governo de responder a esta necessidade por meio de ações que problematizam a agenda da política educacional, é mister resgatar, ainda que brevemente, o modo como concebemos a função social da escola na atualidade.

Não há dissenso em torno da necessária garantia do direito à educação como condição sine qua non de produção da própria existência humana. Por isso, é comum nos textos legais dos mais diversos países formas de proteção imanentes de seu ordenamento jurídico que contemplem e assegurem o acesso, a permanência e, em muitos casos, a qualidade deste direito social expresso, principalmente, por meio da aprendizagem que se materializa numa instituição especialmente criada para este fim: a escola.

A escola, portanto, torna-se o lócus privilegiado para a materialização do direito à educação, fato que só é assegurado quando este sujeito de direito - a despeito de suas condições e/ou características externas e anteriores à escola - aprende em quantidade e qualidade consideradas suficientes. Desse modo, para que esta potencialidade da escola transforme-se em realidade, é necessário organizá-la de modo tal que todos os sujeitos envolvidos com o processo educativo, nas mais diferentes instâncias de poder e de atuação, organizem o seu trabalho para a consecução deste fim. Não obstante, essa organização não se reduz a prescrições técnicas e apresenta-se, também, como arena de disputa para implementação de projetos educativos distintos. É nesta correlação de forças que se produzem as respostas políticas às necessidades educacionais que se inserem na agenda da política educacional.

Por conseguinte, foi na disputa de significados legitimados nos espaços oriundos da simultaneidade de influências - construídas na interlocução entre os entes federados - que se originou a construção de uma alternativa singular e exequível na educação municipal de Curitiba à demanda de ampliação da hora-atividade, num movimento que priorizou um projeto distinto de educação, o qual também exigiu uma resposta distinta do poder público.

Nesse ínterim, para compreender a resposta a esta demanda específica da educação pública municipal de Curitiba, devidamente datada e situada, será necessário explicitar, mais amiúde, alguns pressupostos deste projeto educativo que estava e permanece em disputa.

Reiterando o primeiro pressuposto deste projeto educativo - que se imbrica a materialização do direito à educação - cabe destacar que sua principal tarefa é a de socializar, ao máximo, o saber escolar. Tal objetivo não se apresenta como mera fantasia, mas como um compromisso assumido intencionalmente e que toma a potencialidade do trabalho coletivo como elemento indutor da democratização da e na organização escolar. Gramsci (1978) é peremptório ao analisar as possibilidades existentes na realidade.

A possibilidade não é a realidade, mas é também ela, uma realidade: que o homem possa ou não fazer determinada coisa, isso tem importância na valorização daquilo que realmente se faz. Possibilidade quer dizer 'liberdade'. A medida da liberdade entra na definição de homem. Que existam as possibilidades objetivas de não se morrer de fome e que, mesmo assim, se morra de fome, é algo importante ao que parece. Mas a existência das condições objetivas - ou possibilidade, ou liberdade - ainda não é suficiente: é necessário 'conhecêlas' e saber utilizá-las. Querer utilizá-las. 0 homem, nesse sentido, é vontade concreta: isto é, aplicação efetiva do querer abstrato ou do impulso vital aos meios concretos que realizam essa vontade. (GRAMSCI, 1978, p. 47)

Neste momento histórico, se de um lado ainda não existiam todas as condições objetivas para materializar a ampliação da hora-atividade para $1 / 3$ da jornada de trabalho, de outro já havia consenso acerca do papel articulador deste tempo pedagógico na organização coletiva do trabalho escolar. Esse consenso era expressão de uma vontade concreta que permitiu atrelar essa demanda nacional a uma resposta peculiar do município de Curitiba.

A possibilidade real de construir alternativas distintas às demandas locais se deve àquela simultaneidade de múltiplas influências que se defrontam nos espaços que se abrem para disputas de significados destas políticas. Assim, não tem um peso menor o horizonte postulado pelo projeto educativo em disputa, o qual toma a natureza do trabalho educativo na perspectiva apresentada por Saviani (1991), caracterizando-o como: 
(...) 0 ato de produzir, direta e intencionalmente, em cada indivíduo singular, a humanidade que é produzida histórica e coletivamente pelo conjunto dos homens. Assim, o objeto da educação diz respeito, de um lado, à identificação dos elementos culturais que precisam ser assimilados pelos indivíduos da espécie humana para que eles se tornem humanos e, de outro lado e concomitantemente, à descoberta das formas mais adequadas de atingir esse objetivo (SAVIANI, 1991, p. 21).

Compreende-se, assim, que o trabalho educativo é um dos meios pelos quais se reproduz a própria existência humana, pois "o conjunto da atividade social não pode se reproduzir se não é reproduzida nos indivíduos a humanidade produzida historicamente". (DUARTE, 2007, p.50). Por isso, com a complexificação da sociedade capitalista, a reprodução da existência humana passa a exigir formas mais sofisticadas de formação enquanto processo educativo direto e intencional, as quais serão organizadas nas instâncias que denominamos educação escolar.

O trabalho educativo que se desenvolve no espaço propriamente escolar é caracterizado por Gramsci (1978), Saviani (1991) e Paro (2001) como trabalho não-material, ou seja, não se produz algo imediatamente tangível, pois durante a "aula" - atividade singular do ensino escolar - produção e consumo são indissociáveis; mais do que isso, aluno e professor não se reduzem, respectivamente, ao papel de consumidor e produtor. No processo pedagógico, há uma simbiose entre produção e consumo que gera uma transformação na personalidade e na práxis dos sujeitos envolvidos neste processo. A apropriação da experiência sócio-histórica deixa marcas indeléveis no desenvolvimento psíquico do indivíduo.

Diferentemente do animal, cujo comportamento tem apenas duas fontes - 1) os programas hereditários de comportamento, subjacentes no genótipo e 2) os resultados da experiência individual - a atividade consciente do homem possui ainda uma terceira fonte: a grande maioria dos conhecimentos e habilidades do homem se forma por meio da assimilação da experiência de toda humanidade, acumulada no processo da história social e transmissível no processo de aprendizagem. (...) A grande maioria de conhecimentos, habilidades e procedimentos do comportamente de que dispõe o homem não são o resultado de sua experiência própria, mas adquiridos pela assimilação da experiência histórico-social de gerações. Este traço diferencia radicalmente a atividade consciente do homem do comportamento do animal (LURIA, 1979, p. 73)

Considerando tais pressupostos, a atividade educativa, para ser plenamente cumprida em seu papel de produção e reprodução da vida social, precisa ser intencionalmente organizada, precisa caracterizar-se pela ação consciente e planejada, ou seja, não há espaço para o improviso na educação escolar. Ao formar os indivíduos por meio da seleção dos saberes escolares e dos meios mais adequados para assimilá-los, é preciso definir para que sociedade ele será formado e para que tipo de prática social.

Destarte, assevera-se com tais fundamentos que a instituição escola, no cumprimento de seu papel social, não comporta qualquer trabalho; tampouco é possível realizar plenamente a atividade educativa - na concepção abordada - com a execução individual (ainda que eficaz) dos diferentes sujeitos que operam na escola. O que se quer asseverar é que o ponto de partida do projeto em disputa para construir políticas que respondessem às demandas da agenda tomou o trabalho coletivo como elemento fundante.

Ao tensionar a organização coletiva da escola no seu modus operandi, destacou-se as potencialidades do trabalho coletivo na geração de inteligência singular para responder e solucionar os problemas da instituição. Entretanto, este não é um processo prescritivo que, numa via prussiana, altera o trabalho docente e o caráter formativo de toda a estrutura educacional.

O trabalho docente, ao imbricar-se a socialização de saberes e a formação de sujeitos em relações sociais complexas, exigirá em qualquer mudança o repensar das formas, do conteúdo, da organização curricular, do projeto político-pedagógico, enfim, uma mudança da cultura escolar já encerrada em seu cotidiano.

Desse modo, não se pode desconsiderar que após a entrada da demanda na agenda política, durante sua problematização e construção de alternativas factíveis legitimamente disputadas e no interregno de sua implementação, há um diapasão que ainda permitirá movimentos de resistência e ressignificações. APPLE (1989) e GIROUX (1983 e 1986) tratam com aprofundamento as formas de resistências no processo educativo. Para Giroux: 
La teoría de la resistencia rechaza la idea de que las escuelas son sitios simplemente instruccionales, no sólo politizando la noción de cultura sino analizando también las culturas escolares dentro del convulsionado terreno de la lucha y la protesta. En efecto, esto represen- ta un nuevo contexto teórico para comprender el proceso de escolarización que ubica el conocimiento, valores y relaciones sociales educativas dentro del contexto de relaciones antagónicas y las examina dentro del interjuego de las culturas escolares dominante y subordinado (GIROUX, 1983, p. 52)

Giroux também esclarece em sua obra o quanto as resistências construídas no ambiente escolar podem servir tanto à reprodução quanto à transformação de uma dimensão teleológica inscrita no modo como se organiza a escola e o processo de ensino e aprendizagem. Por isso, enfatiza a necessidade de se considerar os professores como intelectuais transformadores.

Assim, sem desconsiderar o movimento de ressignificação e resistência decorrente da implementação de qualquer política educacional, é possível afirmar que a "Lei do Piso", como ficou conhecida a Lei Federal n. ${ }^{\circ}$ 11.738/2008, com sua demanda nacional, criou uma janela política para o município de Curitiba construir respostas políticas locais indutoras do trabalho coletivo.

A seguir, será detalhado o movimento político de reinterpretação e ressignificação da demanda local frente a uma determinada política nacional, considerando a Abordagem Sequencial.

\section{Entre a problematização e a inscrição na agenda: a gênese da ação pública}

O objetivo deste trabalho é analisar e sistematizar o processo de ressignificação (no âmbito municipal) de uma política singular inserida na agenda nacional. Trata-se, neste caso específico, da Lei Federal no 11.738/2018, cujo objeto de estudo e análise aqui desnudado versará, exclusivamente, sobre o parágrafo $4 .^{\circ}$ do Art. $2 .^{\circ}$ da referida Lei, o qual trata do tempo destinado à hora-atividade dos professores.

A Rede Municipal de Ensino (RME) de Curitiba já garante, desde 1985, 20\% do tempo da carga-horária docente para atividades de planejamento extraclasse, o qual nunca foi interrompido. Entretanto, esse tempo destinado ao planejamento e à formação docente só passou a ser assegurado como direito dos profissionais do magistério, em âmbito nacional, a partir da Lei de Diretrizes e Bases da Educação Nacional (LDBEN n.o 9.394/96). No Art. 67, inciso V da lei, explicita-se a definição de um período reservado a estudos, planejamento e avaliação, dentro da carga horária de trabalho, como uma das formas de os sistemas de ensino promoverem a valorização dos profissionais da educação (BRASIL, 1996).

Porém, a LDBEN não apresenta o percentual de tempo destinado a esse trabalho. Esse tempo só foi instituído em 2008, pela Lei no 11.738/2008 (Lei do Piso Salarial Profissional Nacional), ao definir que a composição da jornada de trabalho do professor deve ser organizada da seguinte forma: 2/3 (dois terços) deverão ser utilizados para o desempenho de atividades com os educandos e 1/3 (um terço) destinado para a realização de estudos, planejamento e avaliação, dentro da carga horária semanal do professor: "§ 40 Na composição da jornada de trabalho, observar-se-á o limite de 2/3 (dois terços) da carga horária para o desempenho das atividades de interação com os educandos" (BRASIL, 2008).

Recentemente, o Parecer CNE/CEB n. ${ }^{\circ}$ 09/2012, aprovado em 12/04/2012, aponta para a importância dos espaços de formação permanente para os professores, devendo o referido tempo compor sua jornada de trabalho.

0 trabalho do professor vai muito além de ministrar aulas. Para que sua atuação tenha mais qualidade, o professor precisa, além de uma consistente formação inicial, qualificar-se permanentemente e cumprir tarefas que envolvem a melhor preparação de suas atividades em sala de aula, bem como tempo e tranquilidade para avaliar corretamente a aprendizagem e 0 desenvolvimento de seus estudantes (BRASIL, 2012).

Contudo, ao qualificar o uso do tempo destinado à hora-atividade docente, o Parecer n. ${ }^{\circ}$ 09/2012 não contemplou, em sua redação, a importância incomensurável deste tempo para a consolidação do trabalho coletivo. Pode-se atribuir esta ausência à inexistência desta demanda em âmbito nacional. Não obstante, não era este o cenário local. 
No município de Curitiba, historicamente este tempo foi denominado de "Permanência"e sua ampliação foi expressão da construção de uma política de indução do trabalho coletivo como elemento indispensável para a consolidação de uma escola pública de qualidade, cuja premissa estabelece que a essência do trabalho educativo é o trabalho coletivo.

Neste aspecto, a política local foi influenciada pela ideia de que uma escola de qualidade passa, necessariamente, pela definição coletiva, como um pacto, sobre o que é uma boa escola. A construção desta escola, portanto, passa pela mão de professores individualmente qualificados, mas não apenas deles, pois como afirmam Freitas et. al. (2011), não se trata de professores individualmente reflexivos, mas de escolas coletivamente reflexivas.

Nossa tese está baseada, portanto, na ideia de que não é apenas o professor que precisa ser reflexivo, mas sim o conjunto da escola (...). É preciso retirar o professor de seu 'narcisismo reflexivo' e reinseri-lo no coletivo escolar, este último com legitimidade para discutir 0 desempenho daquele em uma perspectiva construtiva (FREITAS et. al., 2011, p. 34)

Considerando estes pressupostos iniciais, é indispensável relembrar que a análise da compreensão e da sistematização da política em tela percorrerá, metodologicamente, os princípios da "abordagem sequêncial"de Muller e Surel (2002), pois entende-se que, neste momento, esta é a abordagem mais qualificada para efetivar a intenção deste trabalho.

Cabe destacar ainda que, em que pesem os fundamentos teóricos desta abordagem, a construção de significados que materializou a política educacional singular de Curitiba se deu a partir do que os autores denominam de "janelas de oportunidades". (2002, p. 142)

Ao fazer uma opção assertiva pela Abordagem Sequencial na análise de uma política educacional local, importa destacar também a concepção de política inerente a este estudo, a qual não se reduz ao seu sentido mais restrito, entendida como a ação exercida pelo governo. A política é uma atividade da sociedade, dos homens e mulheres que a produzem e a organizam, da qual o governo e o Estado são parte constitutiva, mas não representam a sua totalidade.

A polissemia inerente a este conceito pode ser mais bem compreendida na língua inglesa, a qual apresenta três verbetes distintos que ajudam a desnudar os nexos e a complexidade da política. Os verbetes utilizados pelos ingleses são: polity, politics e policies.

O termo polity refere-se mais diretamente à esfera da política, trata-se do campo próprio da política, “(...) faz a distinção entre o mundo da política e a sociedade civil". O verbete politics faz menção à atividade política em geral "(...) a competição pela obtenção dos cargos políticos, o debate partidário, as diversas formas de mobilização." E a denominação policies nos remete à ação pública, trata-se do produto e da implementação das ações do governo e do Estado “(...) designa o processo pelo qual são elaborados e implementados programas de ação pública, isto é, dispositivos político-administrativos coordenados em princípio em torno de objetivos explícitos" (MULLER \& SUREL, 2002, p. 11).

Essa proposição levanta pelo menos três dificuldades: tomar consciência do caráter normativo de todo programa de ação pública com seus fins e objetivos (ainda que estejam explícitos ou não); saber quem define as normas da ação pública; tomar consciência do caráter intrinsecamente contraditório de toda política.

Nesse ínterim, para Muller e Surel (idem, p. 14) "uma política pública éformada, inicialmente, por um conjunto de medidas concretas que constituem a substância 'visível' da política”, e que tal substância pode constituir-se de recursos "financeiros", "intelectuais", "reguladores"e "materiais", além de "produtos".

Além deste detalhamento do desenho do que é a política pública, os autores ainda destacam que em todas as "decisões e ações" provenientes das políticas públicas, há um problema que diz respeito à constituição da "coerência", pois essas (as decisões e ações) acabam distanciando-se das regras ou dos objetivos ao incluir no jogo político um número significativo de atores dos mais variados âmbitos e com os mais diversos interesses.

Muller e Surel (idem, p. 16) são peremptórios ao declararem que a busca da coerência no interior das 
políticas públicas constitui-se numa dificuldade imanente, visto que uma de suas características é que elas (as políticas públicas) são “intrinsecamente contraditórias”, ou como afirmam os autores:

Mas não é menos verdade que toda política pública se caracteriza por contradições, até incoerências, que devem ser levadas em conta, mas sem impedir que se defina o sentido das condutas governamentais. Simplesmente, este sentido não é de forma alguma unívoco, porque a realidade do mundo é, ela mesma, contraditória, o que significa que os tomadores de decisão são condenados a perseguir objetivos em si mesmos contraditórios (MULLER e SUREL, 2002, p. 18).

Assim, toda política pública de um determinado governo estará alicerçada em um fim, ou a um conjunto de objetivos que nem sempre estarão claros, podendo ser apresentados de forma "fluída"ou mesmo "ambígua".

Esta caracterização das políticas públicas se faz necessária pelo fato de que este espaço de fluidez, de ambiguidade ou mesmo de contradição nos fins das políticas encontra-se presente no objeto de estudo aqui apresentado. A legislação que serve de amparo para nossa análise não se posicionou frente aos objetivos e fins a serem atingidos com o tempo de trabalho remunerado que está fora dos " $2 \beta$ (dois terços) da carga horária de desempenho das atividades de interação com os educandos", ficando este tempo relegado a fluidez das interpretações.

É exatamente neste espaço de fluidez das interpretações que se consolidou o que os autores (idem, $p$. $142,143)$ caracterizam de "janela de oportunidades", compreendida como um processo de suspensão do "funcionamento ordinário das instituições e dos atores políticos", o que, por sua vez, "tornam possíveis mudanças de políticas públicas específicas", que em nosso caso se deu pela não definição ou não definição objetiva dos fins a serem buscados com a ampliação da permanência.

Uma vez esclarecido o tema, o objeto de estudo e os propósitos deste trabalho, cabe também destacar as fases ou etapas do método da "abordagem sequêncial", esclarecendo a priori que, mesmo denominada de "sequêncial", estas fases ou etapas não se consolidam de forma estanque, nem tampouco seguem um roteiro cristalizado e inelástico, em que a política se produza objetiva e linearmente na sequência apresentada. As fases ou etapas têm o objetivo de dar organicidade às ações e às decisões públicas, que podem ser de início, como afirmam os autores (idem, p. 26), "uma confusão indecifrável para o observador".

Portanto, a utilização da "abordagem sequencial”para a análise, interpretação e compreensão das políticas públicas não é uma defesa pela linearidade da sequência ou das fases/etapas, pois a política, por via de regra, se apresenta de forma caótica. Por conseguinte, analisá-las linearmente poderia nos levar a equívocos de compreensão acenados pelos próprios autores:

Apesar dessas reais contribuições, permanece o fato de que a abordagem sequencial das políticas públicas apresenta limites importantes que devem ser sublinhados. Os inconvenientes mais evidentes desta abordagem dizem respeito à visão por demais linear da ação pública que ela propõe. Ela pode conduzir o analista pouco atento a subestimar o caráter muitas vezes caótico das políticas públicas. Assim, não é raro que se tenha que estudar um processo de decisão no momento em que a fase de identificação do problema sequer teve lugar (MULLER e SUREL, 2002, p. 28).

Muller e Surel (2002) ainda destacam que tanto pode haver etapas inexistentes em uma determinada política implementada como também sua ordem pode estar invertida. Feita esta ressalva passamos a caracterizar a fase/etapa da abordagem sequencial que trata da "colocação na agenda".

Os autores citados apontam a "colocação na agenda" como sendo o momento em que uma dada política passou a caracterizar-se em problema a ser tratado pelo poder público. Afirmam eles que este momento "marca as condições de gênese da ação pública e segue uma multidão de caminhos possíveis" (MULLER e SUREL, 2002, p. 26).

No caso aqui analisado, a “colocação na agenda"se deu por conta de uma 'brecha' de significação deixada na Lei do Piso (Lei no 11.739/2008). Esse espaço constituiu-se em arena de disputa para consolidação de distintos significados oriundos de grupos e movimentos também diversos e, relembrando, Mainardes (idem, p. 9) cabe frisar que a "formulação de políticas é entendida como uma arena de disputa sobre significados". 
No âmbito do sistema federal, o Conselho Nacional de Educação posicionou-se com a produção material de dois pareceres e, no âmbito do sistema municipal, a Secretaria Municipal da Educação de Curitiba ressignificou, por meio de sua ação pública, a finalidade da referida Lei.

O preenchimento da lacuna deixada pela legislação nacional, aspecto que caracterizou a demanda da política, reverberou naquilo que os autores Muller e Surel (2002, p. 108) destacam como sendo a forma pela qual cada administração interpreta seus problemas e dá a eles as suas possíveis soluções com base em seu histórico na gestão das políticas. "Cada administração vai construir, com efeito, uma representação do problema que Ihe é espec ífica, em função de sua história, de seu lugar na divisão do trabalho político-administrativo (...)”, e, neste caso, cabe esclarecer que o Município de Curitiba já apresentava, desde 1985, um elemento histórico sobre a composição da carga horária do professor, fato que apresenta uma potencialidade distinta para preencher a lacuna deixada pela legislação federal, diferente de outras administrações.

No Município de Curitiba, desde 1985 existe a proteção jurídica para os professores exercerem suas atividades extraclasse. Esta garantia foi efetivada na Lei $n^{\circ} .6761 / 85$, que em seu Art. 20, parágrafo $1 .{ }^{\circ}$ declara:

Art. 20 - A jornada semanal de trabalho do Magistério é constituída de horas-aula, horas-permanência e horas-atividade. $§ 10$ - 0 integrante do Quadro Próprio do Magistério, salvo o disposto no artigo seguinte, terá na sua jornada de trabalho um mínimo de vinte por cento (20\%) de horas-permanência semanais para atividades extraclasse (Grifo nosso).

O artigo citado demonstra que, em Curitiba, a política educacional já apresentava alternativas para a composição da jornada de trabalho docente incluindo as atividades extraclasse desde 1985. Não obstante, as alternativas produzidas para solucionar tais problemas sempre estiveram vinculadas, como não poderia deixar de ser, a um determinado projeto educacional.

É mister destacar que, com os debates oriundos da aprovação da Lei Federal no 11.739/2008, impuseramse demandas locais que ainda não estavam presentes nacionalmente. De modo geral, tratava-se de garantir condições mínimas para o desempenho das ações pedagógicas dos professores incluídas em sua jornada semanal de trabalho. Em Curitiba, como este tempo já havia há muito sido garantido (ainda que em percentuais menores), a demanda já se encontrava em outro patamar, qual seja, o de dar significado ao tempo em que os professores não estão em contato direto com os educandos.

Assim, a demanda que se caracterizou no município de Curitiba em termos da implementação do Art. 2. ${ }^{\circ}$, parágrafo $4 .^{\circ}$, da Lei do Piso, foi distinta do movimento engendrado em outras administrações, pois enquanto o município apresentava a necessidade de transformar o tempo extraclasse dos professores em um espaço de consolidação do trabalho coletivo, em âmbito nacional assistia-se o empenho do Conselho Nacional de Educação em preencher e qualificar a lacuna deixada na Lei acerca da necessidade do tempo destinado à hora-atividade em sua vinculação à melhoria das condições de trabalho para os professores.

É possível perceber esta diferença de demanda ao dirigirmos o olhar para os pareceres do Conselho Nacional de Educação que trataram do tema: o Parecer no 09/2012 e seu reexame, o Parecer no 18/2012. Em ambos, a parecerista (que é a mesma) destaca a conquista do Piso Salarial como fruto de "uma luta histórica dos educadores brasileiros", enriquecendo seu parecer inclusive com elementos históricos da política educacional em que o tema é tratado, afirmando que:

0 piso salarial profissional nacional é uma luta histórica dos educadores brasileiros. A primeira referência a um piso salarial nacional data de 1822, registrada em portaria imperial. 0 piso chegou a ser promulgado em 1827, mas não foi implementado. Nesses quase dois séculos, a luta pelo piso salarial nacional do magistério nunca cessou. (PARECER № 9/2012, p. 4 e PARECER № 18, p. 6).

O destaque que se faz aqui diz respeito à caracterização da demanda, ou seja, ao reconhecimento social da necessidade de se regulamentar o piso salarial de todos os professores das escolas públicas do país.

Mais a frente, ambos os pareceres fazem menção ao significado do conteúdo descrito no Art. 2. ${ }^{\circ}$, parágrafo 4. ${ }^{\circ}$, esclarecendo que "não há sentido e nem possibilidade lógica em se afirmar que será pago determinado valor a um profissional sem que se diga a que se refere este valor". Assim, compreende-se que o referido 
artigo da Lei 11.738/2008 regulamenta o que corresponde à paga caracterizada pelo piso: o trabalho realizado diretamente com os estudantes e aquele que não é realizado diretamente com o discente.

Muito embora a parecerista esclareça que o documento em questão não se propõe a esgotar o debate frente ao tema, há que se considerar que se trata de um posicionamento institucional, visto que o mesmo foi amplamente debatido e aprovado pelo Conselho Nacional de Educação, e que este posicionamento não preenche as brechas atinentes a Lei Federal n 11.738/2008, especialmente quando se trata da definição da natureza do trabalho docente exercido fora de sala de aula e sem a presença de estudantes.

Nesse ínterim, tendo a Lei detalhado o processo de implementação de um dos elementos constitutivos de seu conteúdo (o Piso Salarial) e deixado em aberto o outro (1/3 da carga-horária dos professores dedicado a atividades que eles não tenham interação com os estudantes), este último ficou, por assim dizer, órfão de horizonte. Desse modo, por mais que saibamos da importância da hora-atividade para a consecução de tarefas como planejamento, correção de atividades, trabalhos, avaliação e outras ações pedagógicas, este processo acabou não sendo regulamentado, abrindo a possibilidade de que a demanda deste tempo se materialize sob os auspícios do interesse privado e individual de cada professor.

Observa-se que os Pareceres 9 e 18 (2008, p.4 e p.7) expressam a necessidade indelével de se qualificar este tempo de trabalho exercido fora de sala de aula ao declararem que"quando se afirma que vai se pagar certa quantia por determinado trabalho, há que se explicar qual é a quantia e qual éo trabalho". Não obstante, se percebe a ausência, nos mesmos Pareceres, de fundamentos que atrelem o trabalho que está mencionado na Lei do Piso ao trabalho coletivo, condição sine qua non para a realização do trabalho propriamente pedagógico. O parecer (p. 12) ainda apresenta a ideia (com a qual concordamos) de que o sistema econômico e social no qual a educação escolar encontra-se inserida"dissocia, alija o ser humano da sua condição de sujeito histórico e social”. É aqui que se caracteriza com maior veemência a lacuna referente à possibilidade de ressignificação do tema 'trabalho educativo', pois, no espaço das escolas públicas, as relações que ali se efetivam precisam ultrapassar esta perspectiva, e é este o elemento que foi retomado na política educacional para as escolas públicas municipais, qual seja: o trabalho coletivo.

\section{Interfaces, consensos e dissensos no percurso da produção de alternativas, da decisão e da implementação das políticas educacionais locais (policies)}

A complexidade da ação pública e de sua expressão no corpo das políticas faz da Abordagem Sequencial, quando não tomada linearmente, uma metodologia muito assertiva para descrever e analisar formalmente uma determinada policies. Reiterando, assim, os pressupostos já destacados anteriormente, far-se-ãoalguns destaques às etapas que se referem à produção das alternativas, à decisão propriamente dita e ao processo de implementação da política de ampliação do tempo de Permanência em Curitiba, sem, no entanto, tratá-las de modo estanque.

O processo de implantação integral da Lei Federal 11.738/2008 no município de Curitiba esteve atrelado à garantia de 1/3 (um terço) da carga-horária destinada a atividades que não envolvam estudantes e a regência de classe. O cumprimento integral da Lei 11.738/2008 implicava, neste caso particular, em ampliar o período já destinado, no município, à Permanência.

Na Rede Municipal de Ensino (RME), o horário de Permanência - período da carga-horária semanal sem regência de classe - constitui-se como um espaço/tempo destinado aos processos de planejamento, estudo e avaliação do trabalho pedagógico. Nesse período, os profissionais da educação também podem participar de eventos de formação continuada ofertados pela mantenedora.

Ao considerar que este tempo de permanência (hora-atividade) já existia na RME de Curitiba desde 1985, seria suficiente, neste momento histórico, apenas ampliá-lo, passando de $20 \%$ para 33,33\% da jornada de trabalho 
docente semanal. Tal solução permaneceria com a lógica já construída e sairia mais barato economicamente para o município.

Na gestão que se encerrou em dezembro de 2012, a implantação dessa Lei implicou na ampliação gradativa do percentual de permanência dos professores. Assim, em 2012, foi garantido o percentual de 29\% (vinte e nove por cento) ou 6 (seis) horas-aula para permanência. Essa ampliação considerou, inicialmente, apenas o direito do docente. As escolas organizavam-se para garantir os 29\% de permanência sem retomar, necessariamente, a centralidade do direito do estudante à educação e a aprendizagem subjacentes a esta ampliação de tempo.

Em 2013, a SME subverteu essa lógica primando pela promoção e pela garantia do direito à educação. Assim, os esforços empreendidos para que fosse construído um novo projeto educativo que garantisse, entre outras mudanças previstas em sua materialização, o percentual de 33,33\% ou 7 (sete) horas-aula de permanência aos professores foram balizados pela promoção do direito à educação e pela potencialidade que tal procedimento ensejava na ampliação da aprendizagem e na consequente redução da dispersão no rendimento escolar do conjunto dos estudantes. Cabe destacar que o objetivo não era mais unicamente ampliar o tempo de permanência, mas concretizar um projeto pedagógico cujo cerne de seu planejamento se faz sob a égide do trabalho coletivo. Esse novo projeto - que também ampliou o tempo de permanência - permitiu reorganizar o trabalho escolar criando políticas educacionais indutoras do trabalho coletivo.

Assim, a despeito dos movimentos contrários, dos obstáculos e das contradições próprias da movimentação política, o município de Curitiba optou pela organização de um novo projeto educativo, o qual potencializou pedagogicamente os preceitos legais da Lei Federal. Não se tratou de ampliar o tempo de Permanência para cumprir uma determinação legal, mas de implementar um novo projeto pedagógico cujos princípios e pressupostos exigiam, para sua consolidação, além do tempo ampliado de Permanência, sua ressignificação pedagógica como espaço de materialização do trabalho coletivo.

Em relação à organização do trabalho escolar, considerando o projeto pedagógico proposto, as escolas foram orientadas para que organizassem um trio de professores regentes a cada duas turmas: dois regentes de turma e um terceiro regente que assume o componente curricular de Ciências e as atividades de corregência nessas duas turmas. Essa organização baseia-se no pressuposto do trabalho coletivo na medida em que esses profissionais podem ter $20 \%$ do total de seu tempo de permanência em conjunto, para efetivar um trabalho integrado no planejamento do ensino e assumir a corresponsabilidade pelo processo ensino-aprendizagem dos estudantes. Procurar-se-á representar com a Figura 1 a organização inicial deste primeiro coletivo formado pelo trio de regentes.

FIGURA 1 - Distribuição semanal da carga-horária do docente entre atividades de regência de classe e permanência.

\begin{tabular}{|c|c|c|c|}
\hline \multicolumn{3}{|c|}{ Carga-horária semanal remunerada: 20 horas } \\
\hline \multicolumn{2}{|c|}{ Permanência } & \multicolumn{2}{c|}{ Docência } \\
\hline \multicolumn{2}{|c|}{7 horas horas } \\
\hline 4 horas & 3 horas & 9 horas & 4 horas \\
\hline $\begin{array}{c}\text { Permanência coletiva do trio de } \\
\text { regentes }\end{array}$ & Permanência individual & Docência individual & $\begin{array}{c}\text { Docência compartilhada } \\
\text { (corregência) }\end{array}$ \\
\hline
\end{tabular}

Esse conjunto de considerações acerca da materialização do projeto educativo do município de Curitiba que prevê a ampliação do tempo de Permanência para 1/3 da carga-horária semanal da jornada de trabalho docente expressa a potencialidade local na redefinição dos problemas educacionais que alcançaram sua inscrição na agenda política. 
Por tratar-se de uma política (policies) ainda em andamento, não será possível, neste momento, olhar mais amiúde os processos de implementação e de avaliação.

\section{À guisa de conclusões}

A realização deste estudo sobre as marcas distintivas das políticas educacionais locais destinadas a induzir o processo de organização coletiva do trabalho pedagógico escolar a partir das brechas deixadas pelas políticas nacionais na disputa por significados revela a potencialidade do pacto federativo num regime de colaboração em que o diálogo e a corresponsabilidade não retirem nem arrefeçam a autonomia e a responsabilidade dos entes federados no processo de assegurar a materialização plena do direito à educação.

Imbuído deste pressuposto, é mister considerar também que o planejamento da gestão educacional do município - em suas ações e omissões - constitui-se de uma síntese possível da luta política engendrada no campo das políticas educacionais. Sob tal afirmação, toma-se a política como uma 'arena' de disputas em que as relações de poder balizarão o planejamento. IANNI assevera este pressuposto ao reiterar que "(...) o planejamento é um processo que começa e termina no âmbito das relações e estruturas de poder" (IANNI, 1995, p.309)

Destarte, são estas relações e estruturas de poder - construídas e ressignificadas por diferentes atores sociais - que definem e implementam as políticas educacionais. Nesse ínterim, a capacidade política para integrar, em objetivos comuns, os diferentes interesses em disputa no campo da educação é condição sine qua non para a governabilidade.

Isso significa que, para que uma política pública 'exista', é preciso que as diferentes declarações e/ou decisões sejam reunidas por um quadro geral de ação que funcione como uma estrutura de sentido, ou seja, que mobilize elementos de valor e de conhecimento, assim como instrumentos de ação particulares, com o fim de realizar objetivos construídos pelas trocas entre os atores públicos e privados (MULLER \& SUREL, 2002, p. 16 - 17. Grifos do original).

A capacidade política para gerir as políticas educacionais se inscreve, por conseguinte, no movimento da tomada de decisões que exige, deste sujeito político, além do conhecimento da realidade, o domínio da correlação de forças que expressam a possibilidade objetiva de condução e alteração da realidade dada a priori. Tal posicionamento é adensado por Gramsci quando o educador destaca a decisão política que permeia todo processo de planejamento: "Mas a existência das condições objetivas - ou possibilidades, ou liberdade ainda não é suficiente: é necessário ‘conhecê-las' e saber utilizá-las. Querer utilizá-las”(GRAMSCI, 1978, p.47)

Planejamento, Política e Poder estão, portanto, imbricados de tal modo que só é possível separá-los quando nos distanciamos da realidade.

Desse modo, acerca do objeto específico de análise deste estudo, cabe ainda acentuar que não há dúvidas de que a ampliação do percentual da permanência na escola é uma das condições singulares para a valorização dos profissionais da educação, mas, para que de fato colabore para a emancipação do trabalho do professor e do pedagogo, é essencial que este tempo seja qualificado e ressignificado no interior das escolas sob a égide do trabalho coletivo. Esses momentos coletivos permitem reiterar a ideia de que o aluno não é 'deste' ou 'daquele' professor, mas, sim, responsabilidade de toda escola, cujo papel social é materializar e assegurar para todos e para cada um o direito inalienável à educação, entendido como o direito de aprender.

Em que pese o avanço representado pela aprovação da Lei Federal n. ${ }^{\circ} 11.738 / 08$ no contexto do federalismo brasileiro, cabe ainda, localmente, pensar e planejar o tempo destinado à permanência (33\% da carga-horária semanal) para o aprimoramento contínuo do trabalho coletivo orientado à melhoria da qualidade do processo de ensino-aprendizagem nas escolas.

Assim, a despeito de sua origem corporativa, marcada legitimamente pela melhoria das condições de trabalho dos docentes, a ampliação da hora-atividade traz em si, sob a forma de potencialidade, a expansão do direito à educação via qualificação do trabalho escolar, a partir de um novo projeto de escola e de ensino. 
Não obstante, tal projeto não está explícito na ampliação da hora-atividade; ele se põe como necessidade na medida em que projeta uma mudança na organização dos tempos escolares no interior da sala de aula e na gestão pedagógica, ou seja, na medida em que reverbera diretamente no tratamento escolar dado ao conhecimento em sua distribuição temporal.

0 conhecimento, condensação de um distintivo humano, não se materializa por si só, já que necessita de condições específicas para 0 desenvolvimento de suas capacidades. E o foco principal dessas condições mediadoras é 0 aluno. (...) E a escola só é escola porque há aluno e dele decorre a existência do professor. Ora, essa direção em torno do aluno se desenvolve qualificada e plenamente pela mediação do docente e de uma instituição apropriada para tal, a escola (CURY, 2013, p.104).

Com esta afirmação, reitera-se que o 'nascimento' da escola pública, aberta a todos, advêm do Direito à Educação e é em nome desse Direito de Aprender que a escola organiza-se pedagogicamente para cumprir e legitimar o papel dessa instituição: o dever de ensinar. Portanto, é também em nome desse direito que a ampliação da hora-atividade deve organizar-se. Mais do que uma conquista legítima de um segmento da comunidade escolar (docentes), o 1/3 do tempo de trabalho destinado a atividades extraclasse deve representar uma mudança qualificada do ensino, ou seja, deve vir acompanhada de uma nova proposta pedagógica.

As escolas precisam organizar suas rotinas pedagógicas centradas no aprendizado e em altas expectativas de desempenho de seus estudantes, fato que requer - além do trabalho coletivo - clareza na definição do que é essencial na escola em detrimento das inúmeras tarefas que assolam e desviam-se do projeto educativo escolar.

Nesse momento histórico, ampliam-se as condições concretas de planejamento e potencializa-se o exercício do magistério em sala de aula, com os 33\% de Permanência para o docente. Não obstante, a Permanência ampliada exigirá maior responsabilidade e compromisso sobre o uso pedagógico do tempo escolar, maior clareza na definição dos papéis de cada servidor da escola, redimensionamento do trabalho do pedagogo e foco no papel central da escola.

Por fim, mas não em último lugar, há que se destacar a relevância das políticas públicas, não porque a elas coube resolver todos os problemas, mas pela capacidade que lhes sãoinerentes de trazer nova representação aos problemas.

\section{Referências}

APPLE, M. Educação e poder. Porto Alegre: Artes Médicas, 1989.

BRASIL. Constituição (1988). Constituição [da] República Federativa do Brasil. Brasília, DF: Senado Federal. BRASIL. Lei no 11.738/2008. Regulamenta a alínea "e" do inciso III do caput do art. 60 do Ato das Disposições Constitucionais Transitórias, para instituir o piso salarial profissional nacional para os profissionais do magistério público da educação básica. Aprovada em 16 de Julho de 2008. Disponível em: http:// www.seed.se.gov.br/ arquivos/Lei_Piso_Nacional_Magisterio.pdf.

BRASIL. LDB: Lei de Diretrizes e Bases da Educação Nacional : lei no 9.394, de 20 de dezembro de 1996, que estabelece as diretrizes e bases da educação nacional. - 5. ed. - Brasília : Câmara dos Deputados, Coordenação Edições Câmara, 2010. Disponível em: bd.camara.gov.br/bd/bitstream/handle/bdcamara/ 2762/ Idb_5ed.pdf.

BRASIL. Parecer CNE/CEB no 9, aprovado em 12 de Abril de 2012. Implantação da Lei no 11.738/2008, que institui o piso salarial profissional nacional para os profissionais do magistério público da Educação Básica. Disponível em: http://portal.mec.gov.br/index.php? option=com_content\&id=17576\&ltemid=866. (2012a).

BRASIL. Parecer CNE/CEB no 18, aprovado em 02 de Outubro de 2012. Reexame do Parecer CNE/CEB no 9/2012, que trata da implantação da Lei no 11.738/2008, que institui o piso salarial profissional nacional para os profissionais do magistério público da Educação Básica. Disponível em: http:// portal.mec.gov.br/index. php?option=com_content\&id=17576\&ltemid=866. (2012b). 
CURITIBA. Lei no 6761/85, aprovada em 08 de Novembro de 1985. Disponível em: http://cm-curitiba.jusbrasil. com.br/legislacao/735183/lei-6761-85.

CURITIBA. Portaria no 45/2013. Disponibilizada pela Secretaria de Recursos Humanos III do Município de Curitiba. 2013.

CURY, C. R. J. Do direito de aprender: base do direito à Educação. In: ABMP, Todos pela educação (Org.). Justiça pela qualidade na Educação. São Paulo: Saraiva, 2013, p. 104-116.

DUARTE, N. Educação escolar, teoria do cotidiano e a escola de Vigotski. 4a ed. São Paulo: Autores Associados, 2007.

GIROUX, H. Teoria crítica e resistência em educação: para além das teorias da reprodução. Petrópolis: Vozes, 1986.

GIROUX, H. Teorias de la reproduccion y la resistencia en la nueva sociologia de la educacion: un analisis critico. Harvard Education Review No. 3, Buenos Aires. Miami University: 1983

GIROUX, Henry. Escola crítica e política cultural. São Paulo: Cortez, 1987.

GRAMSCI, A. Concepção dialética da História. 2o Ed. Rio de Janeiro: Civilização Brasileira, 1978.

IANNI, O. Estado e planejamento econômico no Brasil. 5 ed. Rio de Janeiro: Civilização Brasileira, 1995.

LURIA, A. R. Curso de Psicologia Geral. vol. I, Rio de Janeiro: Civilização Brasileira, 1979.

MAINARDES, Jefferson. A Pesquisa sobre a Organização da Escolaridade em Ciclos no Brasil (2000 - 2006): mapeamento e problematizações. Revista Brasileira de Educação. Abril: 2009, v. 14, no 40, p. 7-23.

MULLER, Pierre; SUREL, Yves. A Análise das Políticas Públicas. Pelotas: Educat, 2002.

PARO, Vitor Henrique. Gesta冈o democrática na escola pública. São Paulo: Ática, 2001.

SAVIANI, D. Pedagogia histórico-crítica: primeiras aproximações. 2a ed. São Paulo: Cortez e Autores Associados, 1991.

Recebido em Janeiro de 2015 | Aprovado em Fevereiro de 2015 